\title{
Air Purification in a Reverse-Flow Reactor: Model Simulations vs. Experiments
}

\author{
L. van de Beld and K. R. Westerterp \\ Chemical Reaction Engineering Labs., Dept. of Chemical Engineering, University of Twente, NL-7500AE \\ Enschede, The Netherlands
}

\begin{abstract}
The behavior of a reverse-flow reactor was studied for the purification of polluted air by catalytic combustion. $A$ heterogeneous one-dimensional model was extended with a heat balance for the reactor wall. An overall heat transport term is included to account for the small heat losses in radial direction.

The calculations are compared to experimental data without using fit parameters. The agreement between simulations and experiments is generally good. Discrepancies can be explained mainly by inaccurate kinetic data and experimental uncertainties. At low gas velocities and for small reactor diameters, the one-dimensional model failed and a two-dimensional model must be developed to improve the predictive potential.
\end{abstract}

\section{Introduction}

For environmental protection air contaminated with small amounts of volatile organic compounds (VOCs) has to be purified. An attractive process might be catalytic combustion in a reverse-flow reactor, which is sketched in Figure 1. Basically, the reactor works as follows: at startup the reactor bed is preheated to reaction temperature, say around $300-400^{\circ} \mathrm{C}$. Subsequently the contaminated feed is fed to the reactor at ambient temperature. The gas flow is heated by the hot solid phase, and consequently the reactor bed cools down. As a result a "cold" front travels through the reactor toward the outlet. The oxidation reaction takes place in the high-temperature region, and there the temperature rises because of the release of the reaction heat, Figure $2 \mathrm{~A}$. After a certain period of time the direction of the feed flow is reversed and the "cold" front moves in the opposite direction. At the same time the cold part of the bed is heated by the heated gas. This process of flow reversal is repeated continuously. By doing so it is possible to keep the heat inside the reactor, provided that the heat generation by the reaction is high enough to compensate for the convective heat removal from the reactor by the gas phase and for heat losses to the surroundings; see Figure 2B. After a certain number of changes in the flow direction a pseudo-steady-state (PSS) develops, and a hot zone, which moves backward and forward, but never leaves the reactor, has been established in the bed. In such a system

Correspondence concerning this article should be addressed to $K$. R. Westerterp. the heat exchanger and reactor are integrated in one apparatus; this enables autothermal treatment of the polluted air (see, e.g., Matros,1989).

In this article model calculations for the catalytic combustion in such a reactor are compared to experimental results without using fit procedures. Kinetic parameters have been measured independently in a separate installation, and heat and mass transport coefficients are calculated by making use of relations taken from the literature.

Although several articles have been published concerning the modeling of the reverse-flow reactor, only a few compared model calculations to experimental results. Probably the most extensive discussion in this field was given by Gosiewski (1993) for the $\mathrm{SO}_{2}$ oxidation. He compared his own calculations with experimental data from Matros and coworkers. For a proper description of the reactor Gosiewski (1993) found the most important parameter is the interparticle heat transfer coefficient, so a heterogeneous model should always be applied. To describe the experiments satisfactorily an overall radial heat-transfer coefficient that accounted for the radial heat losses had to be introduced. The value was chosen such that the calculated maximum temperature was close to the experimental value. Of course, the maximum temperature is now predicted very well. However, significant discrepancies were still observed in the axial temperature profiles. Possible causes mentioned by Gosiewski were experimental errors, neglect of heat transfer by conduction through the solid phase, and failure of the one-dimensional model used. 


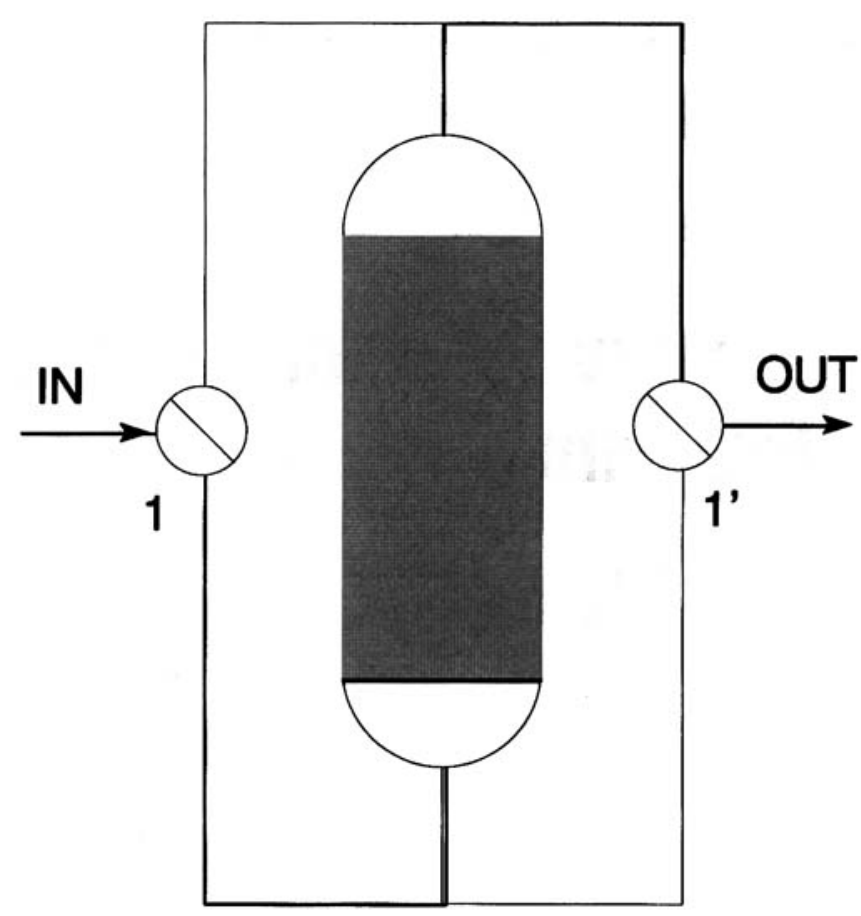

Figure 1. Reverse-flow reactor.

The flow is reversed by appropriate switching the valves 1 and $1^{\prime}$.

A two-dimensional model was developed by Sapundzhiev et al. (1989). They concluded that only for very large reactors with an inner diameter larger than $1 \mathrm{~m}$ heat losses can be neglected. Qualitatively the calculated profiles were in good agreement with the experimental results. However, quantitatively large deviations could be observed. Due to the use of thick layers of insulation a considerable heat buffer had been created. The performance of the model might be improved when the heat capacity of the insulation is considered. Blanks et al. (1990) studied the syngas production in a reverse flowreactor. By applying a large reactor diameter the impact of radial heat losses was suppressed. By a proper adjustment of heat transport coefficients and the kinetic parameters Blanks et al. obtained an acceptable similarity between experiments and calculations. The discrepancies were mainly explained by experimental uncertainties. Schoubye and Nielsen (1993) studied the catalytic combustion of VOCs. The Peclet-number, symbolizing the axial dispersion in the packed bed, could not be predicted accurately from data in the literature, and therefore it was determined such that the simulated profiles fitted the measured profiles. Matros et al. $(1988,1993)$ and Matros (1989) compared calculations and experiments for several processes. Unfortunately, in most cases only the comparison of the overall parameters as the maximum temperature and conversion were reported. In our opinion comparing only the overall parameters does not validate a model. Matros et al. (1993) measured temperature profiles in an industrial reverse-flow reactor, where almost adiabatic conditions were achieved, but still significant deviations were found between model predictions and experiments.

\section{Model}

In van de Beld and Westerterp (1994), a heterogeneous model was presented for the simulation of an adiabatic reverse-flow reactor. That model needs to be refined for an accurate description of the experiments in a laboratory-scale reactor. On a small scale it is hardly possible to achieve complete adiabatic conditions. The nonadiabaticity can be accounted for by heat-loss terms describing the radial heat transport in the packed bed to the wall and heat transport from the reactor wall to the surroundings. An additional heat balance for the reactor wall has to be added. In our experimental equipment the wall thickness is just $1.6 \mathrm{~mm}$, and its heat capacity amounts to about $20 \%$ of the whole system. In the wall heat balance axial heat conduction also has to be considered. Heat conduction through the reactor wall may lead to an apparent increase in axial heat transport in the packed bed. The heat transport mechanisms taken into account in the model are given in Figure 3. The following dimensionless equations describe the extended model:

Solid-Phase Heat Balance:

$$
F_{s}^{*} \frac{\partial \theta_{s}}{\partial \tau}=N T U_{h}\left(\theta_{g}-\theta_{s}\right)+D a \Delta \theta_{a d} \sum r_{j}^{*} H_{j}^{*}
$$
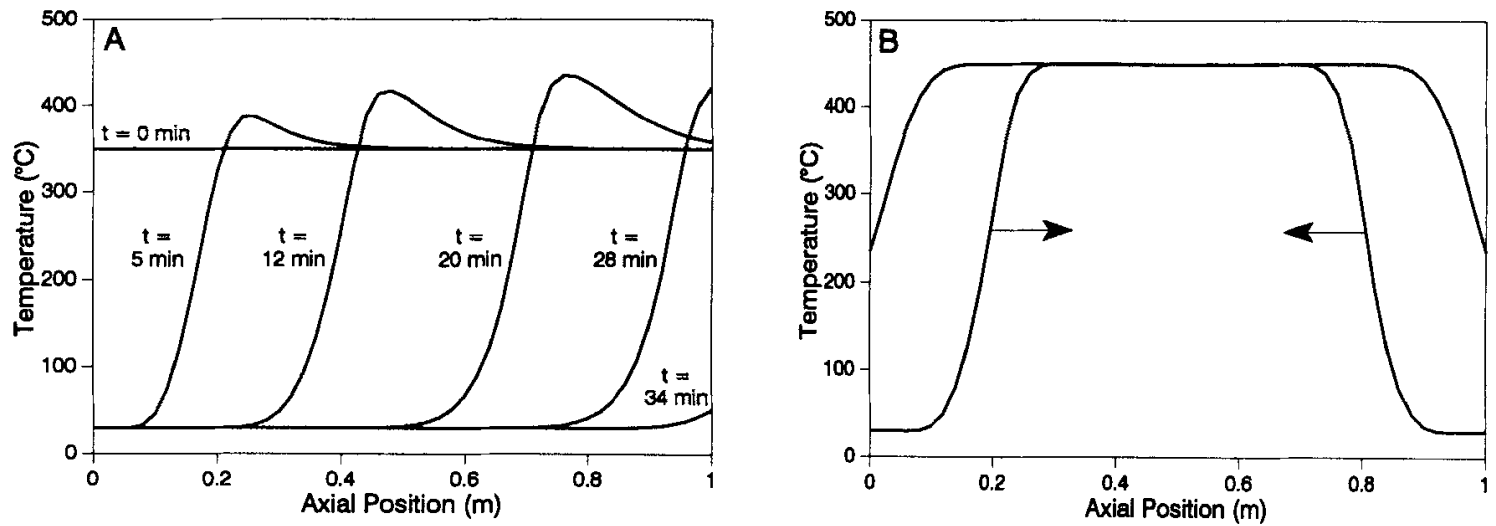

Figure 2. Development of temperature profiles for the oxidation of ethene.

$\Delta T_{a d}=52^{\circ} \mathrm{C}$. (A) without flow reversal. (B) With periodic flow reversal; profiles represent the pseudo-steady-state; cycle period $=10 \mathrm{~min}$. 


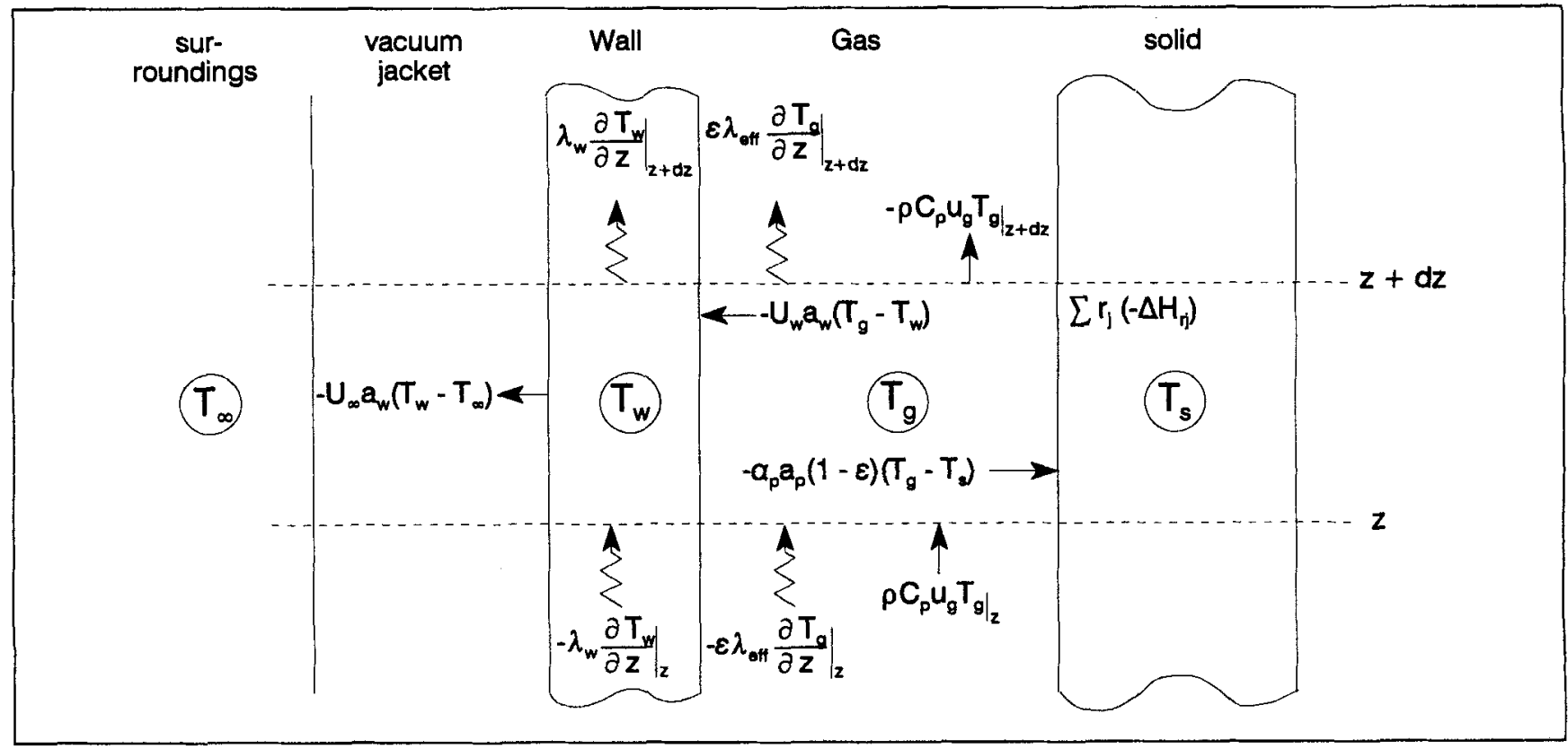

Figure 3. Heat-transport mechanisms taken into account by the simulation model.

Gas-Phase Heat Balance:

$$
\begin{aligned}
0=-\frac{\partial \theta_{g}}{\partial \omega}-N T U_{h}\left(\theta_{g}-\theta_{s}\right)-N T U_{w}\left(\theta_{g}-\theta_{w}\right) & \\
& +\frac{\partial}{\partial \omega}\left(\frac{1}{P e_{h}} \frac{\partial \theta_{g}}{\partial \omega}\right) .
\end{aligned}
$$

Heat-Balance Reactor Wall:

$$
\begin{aligned}
F_{w}^{*} A^{*} \frac{\partial \theta_{w}}{\partial \tau}=N T U_{w}\left(\theta_{g}-\theta_{w}\right)-N T U_{\infty}\left(\theta_{w}-\theta_{\infty}\right) & \\
+ & \frac{\partial}{\partial \omega}\left(\frac{A^{*}}{P e_{w}} \frac{\partial \theta_{w}}{\partial \omega}\right) .
\end{aligned}
$$

Solid-Phase Mass Balance For Component $j$ :

$$
0=N T U_{m j}\left(C_{g j}^{*}-C_{s j}^{*}\right)-D a r_{j}^{*} \quad \text { for } j=1 \ldots k
$$

Gas-Phase Mass Balance for Component $\mathrm{j}$ :

$$
\begin{array}{r}
0=-\frac{\partial u_{g} C_{g j}^{*}}{\partial \omega}+\frac{\partial}{\partial \omega}\left(\frac{C_{t}^{*}}{P e_{m}} \frac{\partial y_{g j}}{\partial \omega}\right)-N T U_{m j}\left(C_{g j}^{*}-C_{s j}^{*}\right) \\
\text { for } j=1 \cdots k,
\end{array}
$$

where $k$ is the number of components present in the feed gas.

Boundary Conditions:

$$
\begin{aligned}
& \omega=0^{-} \quad \theta_{g}-\theta_{g}^{0}=\frac{1}{P e^{*}} \frac{\partial \theta_{g}}{\partial \omega} \quad y_{g j}-y_{g j}^{0}=\frac{1}{P e^{*}} \frac{\partial y_{g j}}{\partial \omega} \\
& \frac{\partial \theta_{w}}{\partial \omega}=0 \quad \omega=1^{+} \quad \frac{\partial \theta_{g}}{\partial \omega}=0 \quad \frac{\partial y_{g j}}{\partial \omega}=0 \quad \frac{\partial \theta_{w}}{\partial \omega}=0 .
\end{aligned}
$$

The boundary conditions are taken outside the reactor just before the inlet at point $0^{-}$and just after the outlet at point $1^{+}$. Closed boundary conditions have been applied to be sure the overall heat balance is satisfied. The value of $P e^{*}$, the Peclet number outside the reactor, is chosen arbitrarily, normally we take $P e^{*}$ equal to $10^{4}$. With such a high value of $P e^{*}$ the influence of the boundary conditions on the calculated profiles has been automatically suppressed completely. A finite difference technique was applied to solve the model. For all calculations $\mathbf{4 0 0}$ grid points have been used. For more details on the numerical method, refer to van de Beld and Westerterp (1994).

\section{Kinetics}

The catalyst used is $\mathrm{Pd}$ on a $\gamma-\mathrm{Al}_{2} \mathrm{O}_{3}$ support (see also Table 1). $\alpha-\mathrm{Al}_{2} \mathrm{O}_{3}$ has been used as inert material for the inand outlet sections of the packed bed. $\alpha-\mathrm{Al}_{2} \mathrm{O}_{3}$ was proved to have no activity for the oxidation reactions below a temperature of $500^{\circ} \mathrm{C}$; see, for example, van de Beld et al. (1994b). For an adequate description of the reactor the kinetic parameters are required; they have been measured independently in a separate installation as described in van de Beld et al. (1994b). The kinetic data given in that article have been measured with dry air. The feed to our reverse-flow reactor always contains about 1 vol. \% water vapor, which inhibits the oxidation rates significantly. The kinetic data in Table 1 have been measured with a feed consisting of hydrocarbons and humid air with 1 vol. \% water vapor. Thus the influence of water on the reaction kinetics is lumped into the data given in Table 1. A first-order reaction rate expression has been used for all three combustion reactions.

\section{Physical properties and transport relations}

The conditions in a reverse-flow reactor will vary over a wide temperature range. Therefore the temperature depen- 
Table 1. List of Input Parameters for the Model Simulations

\begin{tabular}{|c|c|c|c|}
\hline Packed Bed & \multicolumn{3}{|c|}{ Reactor } \\
\hline $\begin{aligned} \epsilon & =0.40 \\
\lambda_{s} & =0.18 \mathrm{~W} / \mathrm{m}^{2} \cdot \mathrm{K} \\
L_{\text {inert }} & =2 * 0.175 \mathrm{~m} \\
L_{\text {catalyst }} & =0.65 \mathrm{~m}\end{aligned}$ & \multicolumn{3}{|c|}{$\begin{aligned} L & =1.0 \mathrm{~m} \\
D_{t} & =0.145 \mathrm{~m} \\
\delta_{w} & =1.6 \mathrm{~mm}\end{aligned}$} \\
\hline Inert & \multicolumn{3}{|c|}{ Reactor wall } \\
\hline $\begin{aligned} \alpha-\mathrm{Al}_{2} \mathrm{O}_{3} & , \text { cylinders } \\
d_{p} & =6.3 \mathrm{~mm} \\
h_{p} & =4.8 \mathrm{~mm} \\
a_{p} & =1,111 \mathrm{~m}^{2} / \mathrm{m}^{3} \\
\rho_{s} & =1,634 \mathrm{~kg} / \mathrm{m}^{3}\end{aligned}$ & \multicolumn{3}{|c|}{$\begin{array}{l}\text { Inconel } 601 \\
\rho_{s}=8510 \mathrm{~kg} / \mathrm{m}^{3} \\
C_{p}=0.450 \mathrm{~kJ} / \mathrm{kg} \cdot \mathrm{K} \\
\lambda_{w}=15.1 \mathrm{~W} / \mathrm{m} \cdot \mathrm{K}\end{array}$} \\
\hline Catalyst & \multicolumn{3}{|c|}{ Kinetics* } \\
\hline $\begin{array}{l}0.08 \text { wt. } \% \mathrm{Pd} / \gamma-\mathrm{Al}_{2} \mathrm{O}_{3} \text {, } \\
\text { cylinders }\end{array}$ & & $\begin{array}{c}E_{\text {act }} \\
(\mathrm{kJ} / \mathrm{mol})\end{array}$ & $\begin{array}{c}k_{\infty} \\
\left(\mathrm{mol} / \mathrm{Pa} \cdot \mathrm{s} \cdot \mathrm{m}^{3}\right)\end{array}$ \\
\hline $\begin{aligned} d_{p} & =4.5 \mathrm{~mm} \\
h_{p} & =4.5 \mathrm{~mm} \\
a_{p} & =1,300 \mathrm{~m}^{2} / \mathrm{m}^{3} \\
\rho_{s} & =1,327 \mathrm{~kg} / \mathrm{m}^{3}\end{aligned}$ & $\begin{array}{l}\text { Ethene } \\
\text { Propane } \\
\text { Propene }\end{array}$ & $\begin{array}{r}67.3 \\
87.6 \\
116.6\end{array}$ & $\begin{array}{l}9.8 \times 10^{2} \\
5.8 \times 10^{3} \\
5.9 \times 10^{8}\end{array}$ \\
\hline
\end{tabular}

${ }^{*}$ Measured with approximately 1 vol. \% water present in the feed flow.

dence of all physical properties, such as specific heat, thermal conductivity, and viscosity, have to be taken into account. Because over $99.5 \%$ of the feed consists of air, for the gas phase the properties of air have been taken as tabulated extensively by L'Air Liquide (1976).

It is often difficult to find reliable relations for the description of heat and mass transport in packed beds. The experimental conditions and the characteristics of the packing, for which these relations have been determined, should be as close as possible to the conditions prevailing in the reactor under investigation. Moreover, the relations must be valid for the specific model used, for example, axial dispersion coefficients determined for a pseudohomogeneous model cannot be used in a heterogeneous model, just as the axial dispersion coefficient cannot be obtained with a model containing both axial and radial dispersion. For example, we could not find an adequate relation for the description of axial dispersion of heat in a packed bed of cylinders. Table 2 lists the relations that have been used in the calculations. Gnielinski (1982) has obtained correlations for the description of interparticle heat and mass transfer in a packed bed of cylinders. Dixon and Cresswell (1979) have reevaluated the experimental results of several authors for the description of axial heat transport in packed beds; the relation obtained is very similar to the correlation for axial mass dispersion given by Edwards and Richardson (1968). The complete Zehner-Bauer model has been used for the description of the effective thermal conductivity of the stagnant bed (see, e.g., Bauer, 1977). This model includes the contribution of radiation to heat transport, which might become important at high temperatures. For packed beds, numerical values of this contribution might be obtained by making use of the method proposed by Vortmeyer (1980). In the simulations all heat-and mass-transfer coefficients have been recalculated for the specific conditions at each axial position in the reactor.

\section{Experimental}

The dimensions of the reactor and the characteristics of the packed bed are given in Table 1. The reactor is equipped with an evacuated jacket to suppress radial heat losses. Such a system is well defined and it allows for a simple determination of the overall radial heat-transfer coefficient. Ethene, propene, and propane have been used as VOC contaminants. A detailed description of the experimental installation and the determination of the overall heat transfer coefficient in the radial direction are given elsewhere (see van de Beld et al., 1994a).

\section{Results and Discussion}

The calculated temperature profiles as a function of time with the preceding model, in which the data just discussed

Table 2. Heat- and Mass-Transport Relations Used in the Calculations

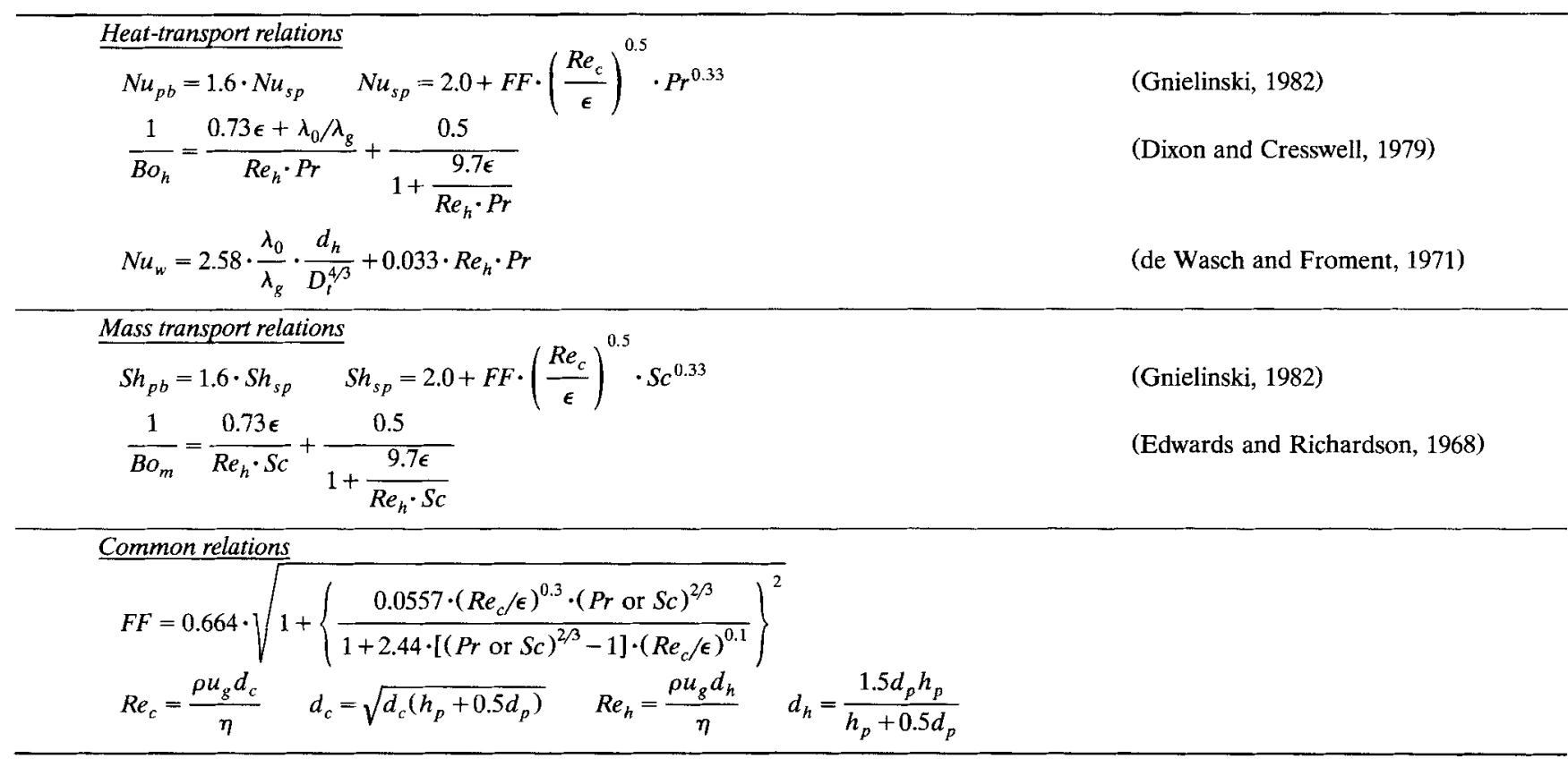


have been put, have been compared to experimentally measured profiles. On the basis of this comparison the significance of the various items in the model will be discussed. For all calculations the numerical values of the parameters required in the model have been determined with the relations and data given in Tables 1 and 2 . We did not attempt to improve our results by adjusting the input values of the parameters. In the figures discussed in the following we show the profiles in the upflow direction just before the flow is reserved. The plateau temperature $T_{\text {plat }}$ is the maximum temperature in the PSS. As soon as the temperature profiles remain constant over a cycle, the reactor has reached the PSS.

\section{Influence of the reactor wall}

The impact of the inclusion of the wall into the model is shown in Figure 4, where the axial temperature profiles in the PSS are given. The heat capacity of the wall is considerable and the wall heat conductivity is high. In the model, heat transport in the radial direction is divided into two parts, from the packed bed to the wall and from the wall to the surroundings, respectively, and denoted $U_{w}$ and $U_{\infty}$. If the contribution of the wall is neglected, these two parts must be combined, such that the total resistance against heat transport in the radial direction remains the same:

$$
\begin{aligned}
\frac{1}{U_{\text {overall }}} & =\frac{1}{U_{w}} \\
\text { or } \quad \frac{1}{N T U_{\text {overall }}} & =\frac{1}{N T U_{w}}+\frac{1}{N T U_{\infty}} .
\end{aligned}
$$

The cycle period is chosen relatively large for the comparison shown in Figure 4, because in that case the influence of the wall is most obvious. The reactor wall acts as an extra heat buffer. For the positions in the reactor where the heat front has just passed, the wall temperature is higher than the bed temperature: this results in a heat flux from the wall into the bed. Behind the heat front, the wall temperature is lower,

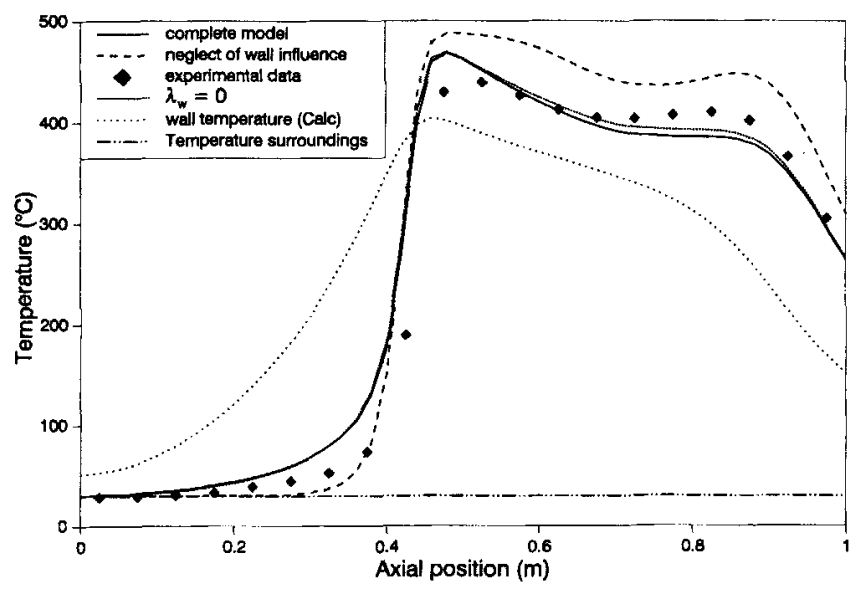

Figure 4. Comparison of calculated temperature profiles to experimental data; effect of including the wall heat balance.

$C_{\text {ethene }}=0.088 \mathrm{~mol} / \mathrm{Nm}^{3} ; t_{c}=1,600 \mathrm{~s} ; u_{g}=0.40 \mathrm{~m} / \mathrm{s} ; P=$ 1.45 bar; $T_{0}=30^{\circ} \mathrm{C}$. and heat is transported from the bed into the wall. The outcome is that the heat is somewhat smeared out over the bed, which may be interpreted as an axial dispersion of heat. Neglecting the wall heat balance gives a steeper profile. The sensitivity of the model with respect to the wall heat conductivity $\lambda_{w}$ is small. The heat flux by conduction through the reactor wall is of the same order of magnitude as the heat flux by axial dispersion in the packed bed: $\lambda_{w} A^{*} / \epsilon \lambda_{\text {eff }} \approx 0.56$. Changing $\lambda_{w}$ over a wide range hardly changed the calculated profiles (see Figure 4). So the change in profiles is mainly caused by the wall heat capacity and not by its conductivity. For small cycle periods the temperature profiles are not affected by the wall, because in that case the wall temperature profile hardly moves over a cycle.

\section{Temperature influence on bed and gas properties}

In Figure 5 the axial temperature profiles in the PSS are plotted for variable and constant physical properties throughout the reactor. For the first case all properties are recalculated for each position (grid point) in the reactor at the temperature prevailing at that position. In the reverse-flow reactor a wide temperature range is covered, so it is doubtful whether the physical properties may be assumed to be constant. The choice of the average conditions at which the parameters should be calculated for the whole reactor also presents a problem. For the calculations in Figure 5 the problem has been approached as follows. Heat transport is important over the whole temperature range, so the heat-transport parameters have been calculated at $T_{\text {calc, heat }}=\left(T_{\max }+T_{\text {feed }}\right) / 2$. Mass transport is unimportant at low temperatures, but becomes so as soon as reactions take place. Therefore the mass-transport parameters have to be calculated at a higher temperature: arbitrarily we chose $T_{\text {calc, mass }}=T_{\max }-\Delta T_{a d}^{0}$. The underlying intuitive assumption here is that the reaction mainly occurs in the temperature range from $T_{\max }-2 \cdot \Delta T_{a d}^{0}$ to $T_{\max }$. This, of course, is not necessarily true, as it depends on $E_{\text {act }} / R$. To make this plausible we calculated the temperature $T_{0.01}$ at which the reaction rate is reduced by a factor of 100 compared to the rate at $T_{\max }$. For the three compo-

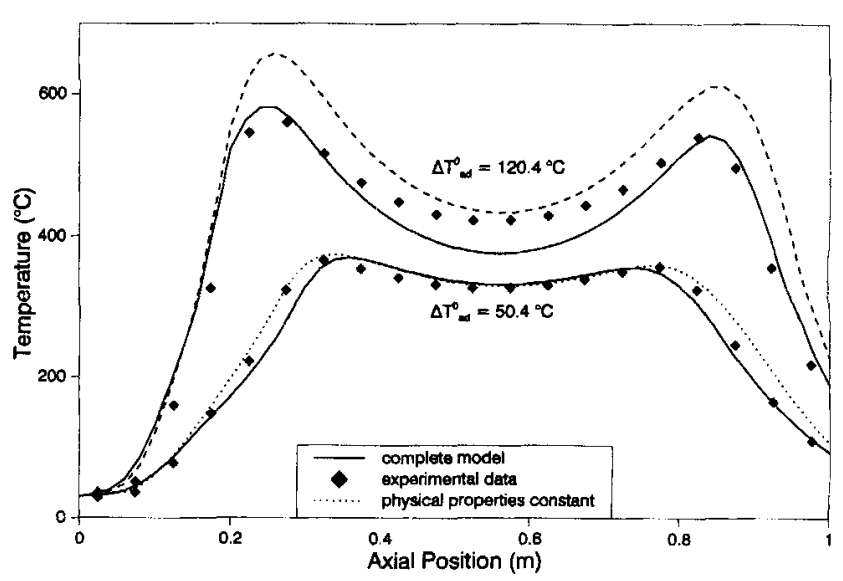

Figure 5. Comparison of experimental and calculated gas-temperature profiles for the oxidation of ethene; impact of keeping the physical properties constant.

$t_{c}=400 \mathrm{~s} ; u_{g}=0.40 \mathrm{~m} / \mathrm{s} ; P=1.45 \mathrm{bar} ; T_{0}=30^{\circ} \mathrm{C}$. 

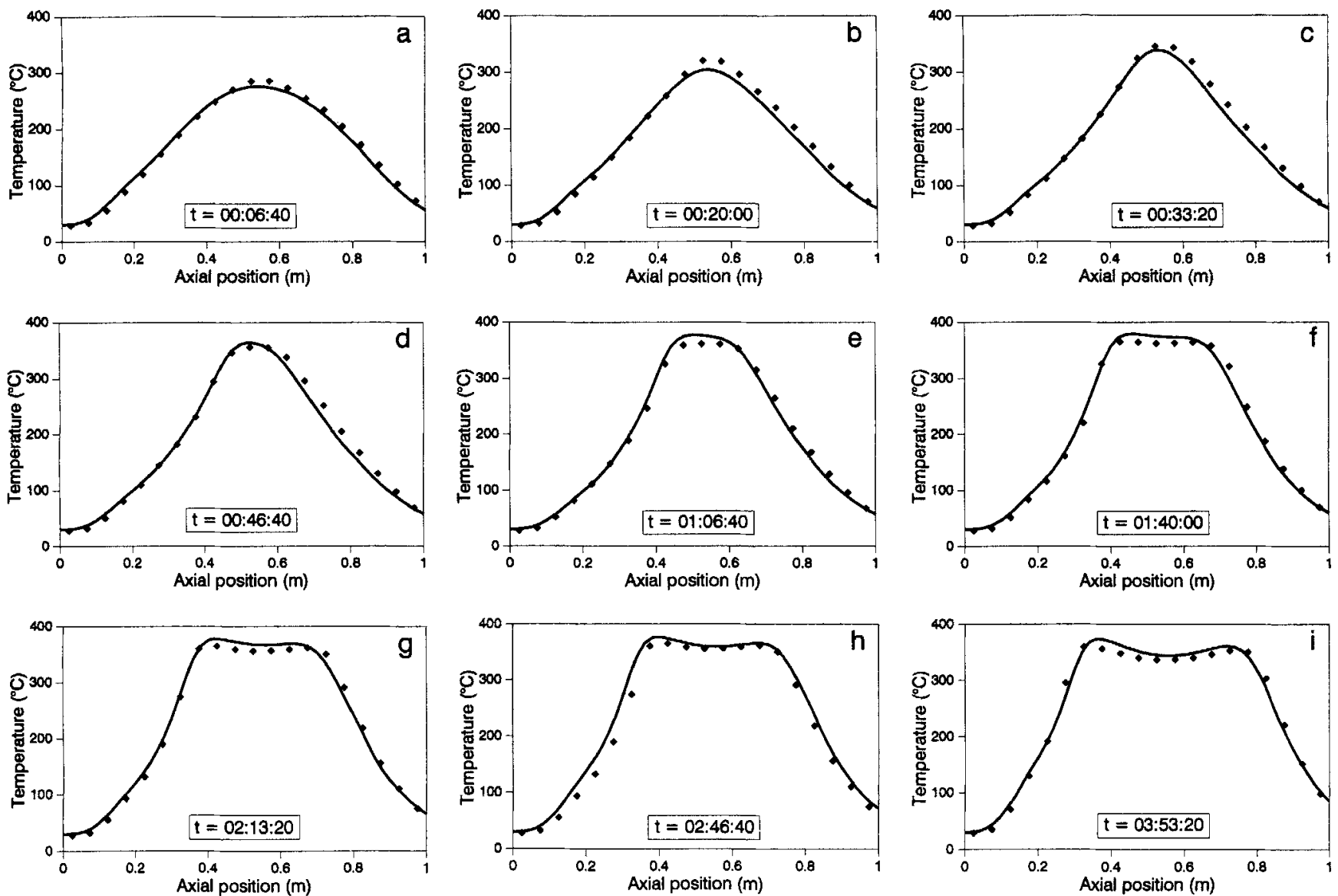

Figure 6. Development of the axial gas-temperature profiles.

- experimental data; - calculated with the complete model. $C_{\text {ethene }}=0.0453 \mathrm{~mol} / \mathrm{Nm}^{3} ; \Delta T_{a d}^{0}=50.4^{\circ} \mathrm{C} ; t_{c}=400 \mathrm{~s} ; u_{g}=0.40 \mathrm{~m} / \mathrm{s} ;$ $P=1.45$ bar; $T_{0}=30^{\circ} \mathrm{C}$

nents, $T_{\max }-T_{0.01}$ has been compared to $\Delta T_{a d}$. For a high $\Delta T_{a d}$ the range was $2.2 \times, 1.9 \times$, and $1.5 \times \Delta T_{a d}$, and for a low $\Delta T_{a d}$ it was $3.3 \times, 3.4 \times$, and $1.8 \times \Delta T_{a d}$ for ethene, propane, and propene, respectively. For a low adiabatic temperature rise the assumption of constant physical properties only slightly modifies the calculated profile (see Figure 5). The sensitivity for improper values of the mass-transfer coefficients is not so large, because the conversion rate is mainly determined by the reaction kinetics and, of course, the temperature dependence of the reaction has been included in the model. For a high $\Delta T_{a d}$ the differences become more obvious and the model significantly overrates the experimental data. For high temperatures the profiles are more sensitive to interparticle mass transport, and therefore assuming constant properties will result in larger errors. But also the errors in heat-transfer coefficients become larger: for example, the value of the interparticle heat-transfer coefficient $\alpha_{p}$ at $600^{\circ} \mathrm{C}$ is about $20 \%$ higher than $\alpha_{p}$ calculated at the mean temperature of $315^{\circ} \mathrm{C}$.

\section{Development of the temperature profiles}

In Figure $6 \mathrm{a}$ to $6 \mathrm{i}$ the experimental and calculated development of the temperature profiles is shown after a change in operating conditions. The experimental profile at $t=0$ is used as the initial profile for the simulations. At $t=0$ both pro- files are exactly equal. For this profile the temperature level is too low to achieve complete conversion of ethene. The highest temperature can be found in the center of the reactor, where the reaction will occur.

In Figures $6 \mathrm{~b}$ to $6 \mathrm{e}$ it can be clearly seen that the temperature in the center increases due to the release of the reaction heat. A further expansion of the profiles in the direction of the in- and outlet of the reactor can be observed in Figure $6 f$ to $6 \mathrm{i}$. From these figures we see that the dynamic behavior of the reactor observed experimentally is predicted very accurately by the model. For this experiment about 35 cycles were required to reach the PSS, so the profiles in Figure 6i correspond to the profiles in the PSS.

\section{Influence of the hydrocarbon concentration and the chemical character of the contaminant}

In Figures 7 and 9 experimental and calculated temperature profiles in the PSS and the heat-production curves are shown for ethene, propene, and propane, respectively, as contaminants. For a low adiabatic temperature rise the maximum temperature will also be relatively low (see Figure 7). This means that the conversion of the contaminants is strongly influenced by the reaction kinetics, and interparticle mass transport plays a minor role. For a reverse-flow reactor it is known that lower reaction rates result in an increase in the 


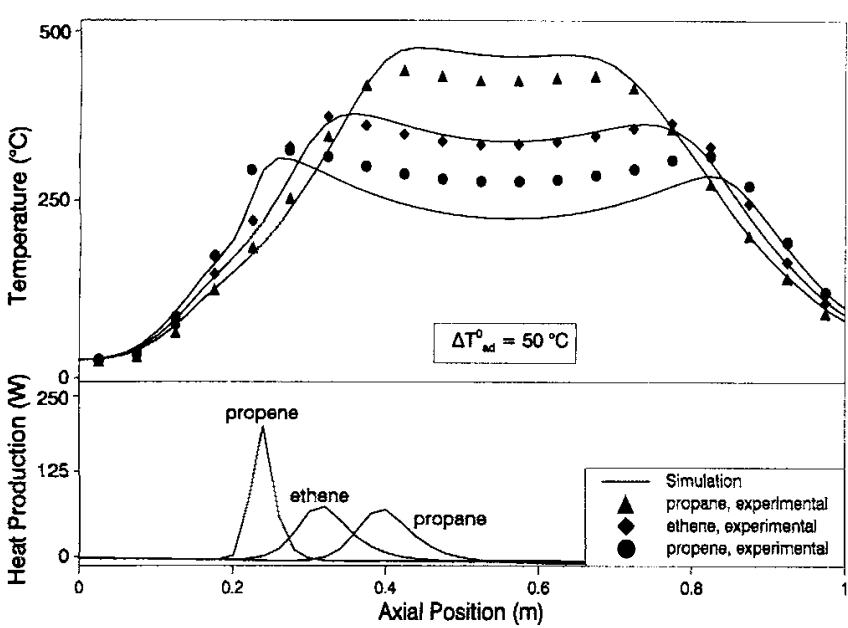

Figure 7. Comparison of axial gas-temperature profiles and heat-production curves for different compounds.

$C_{\text {ethene }}=0.0453 \mathrm{~mol} / \mathrm{nNm}^{3} ; \quad C_{\text {propene }}=0.0311 \mathrm{~mol} / \mathrm{Nm}^{3}$; $C_{\text {propane }}=0.0293 \mathrm{~mol} / \mathrm{Nm}^{3} ; t_{c}=400 \mathrm{~s} ; u_{g}=0.40 \mathrm{~m} / \mathrm{s} ; P=$ 1.45 bar; $T_{0}=30^{\circ} \mathrm{C}$

plateau temperature and a smaller plateau width (see, e.g., Eigenberger and Nieken (1988)). This is confirmed by the experiments and calculations presented in Figure 7. Propene is easy to oxidize and a low $T_{\text {plat }}$ is observed, whereas propane is more stable and higher temperatures are required for complete conversion. This is also illustrated by the heat-production distribution over the reactor that is very different for the three compounds (see Figure 7). For ethene the calculated profile describes the experiments quite accurately. For propene, the model predicts a plateau temperature too low, so probably the conversion rate of propene is overestimated in the model. The reaction rate of propene is high, and even at these relatively low temperatures, the influence of interparticle mass transport is significant. In Figure 8 the masstransfer and the reaction rate constant vs. the temperature is plotted for the three components. For propene the ratio between the reaction rate and the mass transport rate increases

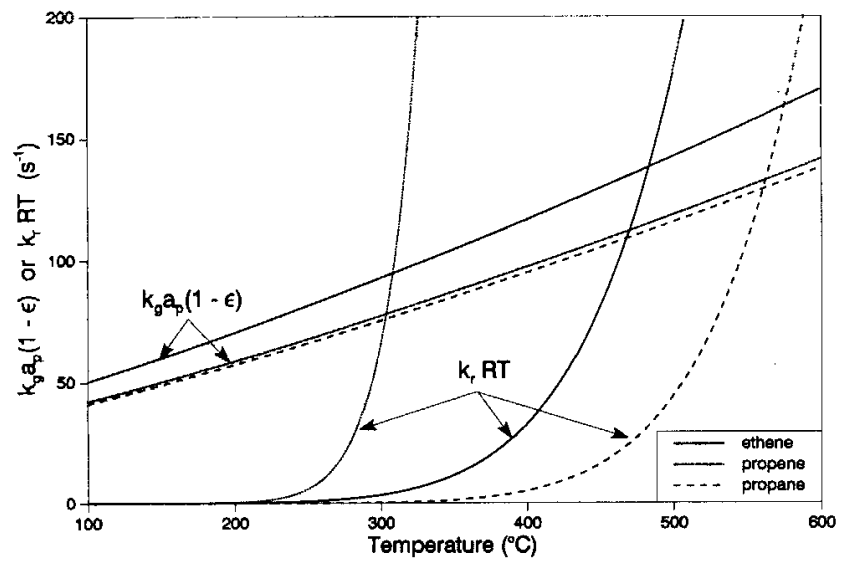

Figure 8. Mass-transfer and reaction-rate constant vs. the temperature for different compounds: $u_{g}$ $=0.40 \mathrm{~m} / \mathrm{s} ; P=1.45$ bar; for correlations and kinetic data see Tables 1 and 2.

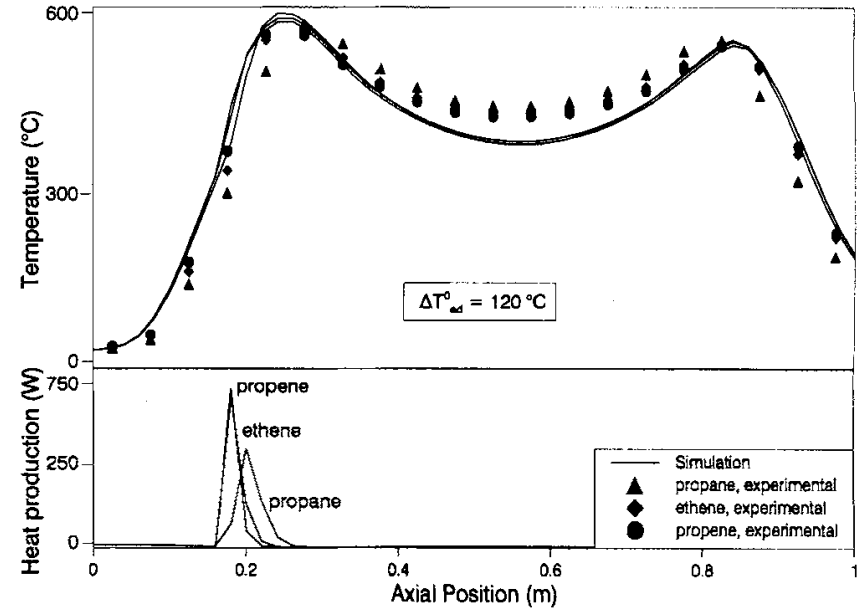

Figure 9. Comparison of axial gas-temperature profiles and heat-production curves for different compounds.

$C_{\text {ethene }}=0.1081 \mathrm{~mol} / \mathrm{Nm}^{3} ; C_{\text {propene }}=0.0743 \mathrm{~mol} / \mathrm{Nm}^{3}$; $C_{\text {propane }}=0.0700 \mathrm{~mol} / \mathrm{Nm}^{3} ; t_{c}=400 \mathrm{~s} ; u_{g}=0.40 \mathrm{~m} / \mathrm{s} ; P=$ 1.45 bar; $T_{0}=30^{\circ} \mathrm{C}$.

from 0.09 to 0.85 when the temperature increases from 250 to $300^{\circ} \mathrm{C}$. For both the ethene and the propane oxidation this ratio remains below 0.2 if it is calculated at the maximum temperatures of the respective experiments. The temperature profiles in the in- and outlet section of the reactor are mainly determined by heat transport, and these parts of the profiles are predicted quite well in all cases (see Figure 7).

Figure 9 shows profiles similar to those depicted in Figure 7, except Figure 9 depicts a high adiabatic temperature rise. Under these conditions the maximum temperature is high and the conversion rate of the contaminants is mainly determined by the interparticle mass-transport resistances, although at $T_{\max }$ the propane reaction rate is just about two times higher than its mass-transfer rate (see Figure 8). Both the simulations and the experiments give nearly the same profiles for all compounds. The agreement between model and experiments is acceptable, although the experiments are systematically underrated in the center of the reactor. The lower mass flux of propane and propene compared to the ethene mass flux (see Figure 8) is counterbalanced by the higher heat of reaction of the former compounds. In all cases the heat-production distribution over the reactor becomes nearly the same, and therefore similar profiles are found (see Figure 9). In Figure 9 it seems that the reaction is completed before the maximum temperature is reached. It should be mentioned that the heat-production profile is instantaneous, whereas the temperature profile itself is determined by the dynamics of the system, for example, it depends on the cycle period.

\section{Influence of the gas velocity}

Figures 10 and 11 depict the influence of gas velocity on temperature profiles, and the plateau temperature is given. For a relatively high gas velocity of $u_{g}=0.50 \mathrm{~m} / \mathrm{s}$, the axial temperature profile experimentally determined is predicted sufficiently well by the model. For a low gas velocity of $u_{g}=$ $0.10 \mathrm{~m} / \mathrm{s}$, the calculated profile deviates significantly from the experimental one. In the experimental setup, the tempera- 


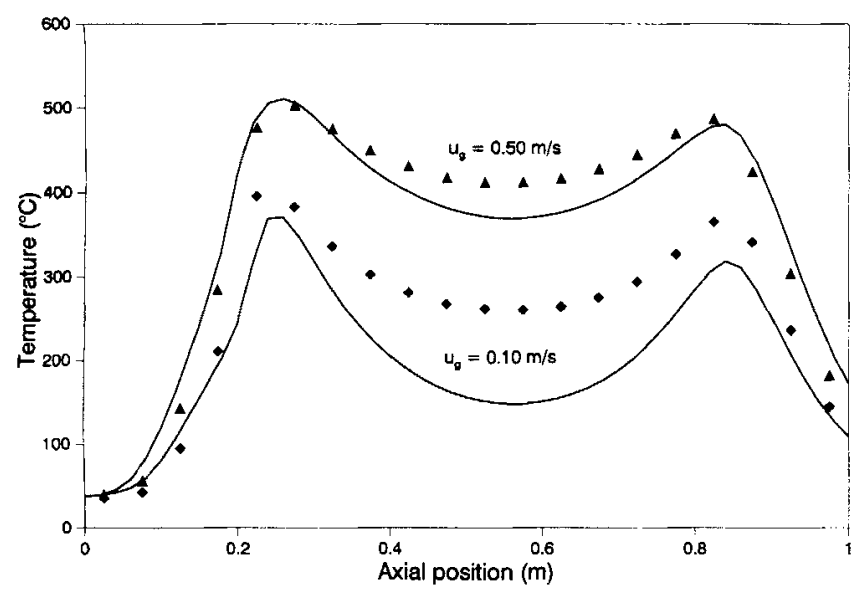

Figure 10. Comparison of experimental and calculated gas-temperature profiles and for different gas velocities.

$u_{\mathrm{g}}^{*} t_{c}=160 \mathrm{~m} ; C_{\text {ethene }}=0.086 \mathrm{~mol} / \mathrm{Nm}^{3} ; \Delta T_{\mathrm{ad}}^{0}=95.7^{\circ} \mathrm{C} ; P$ $=1.06-1.55$ bar; $T_{0}=30^{\circ} \mathrm{C}$.

tures in the reactor are measured on the center axis. If radial temperature gradients in the reactor are significant, the temperature on the center axis will probably give a wrong picture of the average temperature over the radius. At these low gas velocities, radial gradients may become important. The total resistance against radial heat transport can be divided into three separate parts. For the calculations, the relations given by de Wasch and Froment (1972) are used, since the conditions of their experiments are very close to ours. The following results are obtained for a total driving force of $350^{\circ} \mathrm{C}$ :

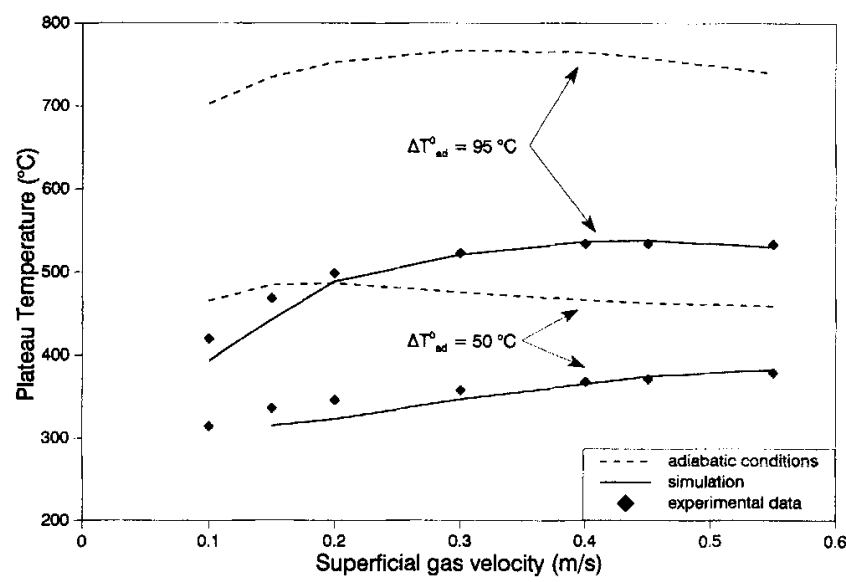

Figure 11. Plateau temperature as a function of the gas velocity: comparison to adiabatic operation. $u_{g}^{*} t_{c}=80 \mathrm{~m} ; P=1.06-1.55$ bar; $T_{0}=30^{\circ} \mathrm{C}$.

served temperatures should be higher than the calculated ones; this agrees with our results (see Figure 10). Sapundzhiev et al. (1989) developed a two-dimensional model to describe the behavior of a reverse-flow reactor and found that the radial temperature gradient normally is not a parabola. Depending on the axial position the temperature near the wall might be even higher than in the center, as already illustrated in Figure 4. A two-dimensional model accounts for possible radial temperature gradients; such a model may be required to improve our results. Another explanation might be found in the reliability of the heat- and mass-transport relations at low Reynolds numbers (see, e.g., Wakao and

Total $=$ Heat transport from + Radial heat transport + Heat transfer through

resistance packed bed to the in the packed bed evacuated jacket to wall the surroundings

$$
\begin{array}{llll}
\frac{1}{U_{\text {overall }}}=\frac{1}{U_{w}}+\frac{1}{U_{\infty}} & =\frac{1}{\alpha_{w}} & +\frac{D_{t}}{6.1 \cdot \lambda_{\text {eff }, r}} & +\frac{1}{U_{\infty}} \\
u_{g}=0.10 \mathrm{~m} / \mathrm{s} & =0.029 & 0.065 & 0.507 \mathrm{~m}^{2} \cdot \mathrm{K} / \mathrm{W} \\
& \Delta T \approx 17^{\circ} \mathrm{C} & \Delta T \approx 38^{\circ} \mathrm{C} & \Delta T \approx 296^{\circ} \mathrm{C} \\
u_{g}=0.50 \mathrm{~m} / \mathrm{s} & =0.011 & 0.029 & 0.507 \mathrm{~m}^{2} \cdot \mathrm{K} / \mathrm{W} \\
& \Delta T \approx 8^{\circ} \mathrm{C} & \Delta T \approx 19^{\circ} \mathrm{C} & \Delta T \approx 324^{\circ} \mathrm{C}
\end{array}
$$

Thus for a low gas velocity the radial temperature gradient is significantly higher, but a severe radial temperature gradient can also be expected for a high gas velocity. Only a onedimensional model (ODM) has been applied, and such a model does not account for possible radial gradients. Parabolic radial temperature gradients are often found for packed-bed reactors, and in that case the temperature on the center axis of the reactor will always be higher than the average temperature. Experimentally, the temperature is measured on the center axis, whereas an ODM predicts the mean radial temperature over the cross-sectional area (see Westerink et al. (1990)). As a consequence, the experimentally ob-
Kaguei (1982)). For $u_{g}=0.10 \mathrm{~m} / \mathrm{s}$, the Reynolds number is just about 30.

In Figure 11 the plateau temperature is plotted as a function of the gas velocity. $T_{\text {plat }}$ is predicted rather well over the whole range. In the same figure the plateau temperature is also plotted as calculated for truly adiabatic conditions. In that case $T_{\text {plat }}$ is higher, of course. In van de Beld and Westerterp (1994) it is shown that a maximum in the plateau temperature is found for the particular gas velocity where $\mathrm{NTU}_{h}$ is equal to $P e_{h}$. The dependence of the heat transfer coefficient on the gas velocity leads to a relatively smaller decrease in $T_{\text {plat }}$ when $u_{g}$ increases: $\mathrm{NTU}_{h} \sim \alpha_{p} / u_{g}, \alpha_{p} \sim u_{g}^{0.5-0.8}$, and 
thus $\mathrm{NTU}_{h} \sim u_{g}^{-(0.2-0.5)}$. In practice, the dependence of $T_{\text {plat }}$ on the gas velocity is small. With increasing temperature the point, where $\mathrm{NTU}_{h}$ equals $P e_{h}$ shifts to a higher gas velocity: for $200^{\circ} \mathrm{C}$ this point is found at $u_{g} \approx 0.15 \mathrm{~m} / \mathrm{s}$ and for $700^{\circ} \mathrm{C}$ at $u_{g} \approx 0.3 \mathrm{~m} / \mathrm{s}$.

Under the experimental conditions the somewhat lower efficiency of interparticle heat transport in the packed bed is overcompensated for by a decrease in the heat losses in the radial direction at higher gas velocities. Consequently, $T_{\text {plat }}$ increases in the experiments.

\section{Influence of nonadiabatic conditions}

The impact of nonadiabaticity is also shown in Figure 12, where the plateau temperature is plotted as a function of the adiabatic temperature rise. Over the whole range $T_{\text {plat }}$ is predicted quite satisfactorily by the model. $\Delta T_{a d}$, min, the minimum adiabatic temperature rise, at which the process becomes autothermal and at which the conversion is high, is somewhat lower than predicted. Under truly adiabatic conditions the calculated plateau temperatures are higher and the calculated $\Delta T_{a d \text {, min }}$ lower than in the experimental installation.

\section{Plateau temperature}

In Figure 13 the experimentally observed and the calculated plateau temperatures are compared. Although we already pointed out that comparing maximum temperatures does not validate a model, it does give an impression of the efficacy of the model over a wide range of operating conditions. In Figure 13 we observe $T_{\text {plat }}$ is predicted accurately: for most experiments $T_{\text {plat }}$ is predicted with a precision of $30^{\circ} \mathrm{C}$ and with a mean error of about $11^{\circ} \mathrm{C}$.

In van de Beld and Westerterp (1994), the countercurrent-reactor (CCR) model was presented for the prediction of the plateau temperature. The prediction of this model is also given in Figure 13: results are very poor. Prediction of $T_{\text {plat }}$ with the relations derived by Matros are useless, because heat losses cannot be taken into account. Even for adiabatic conditions these expression give poor results (see van de Beld and Westerterp, 1994).

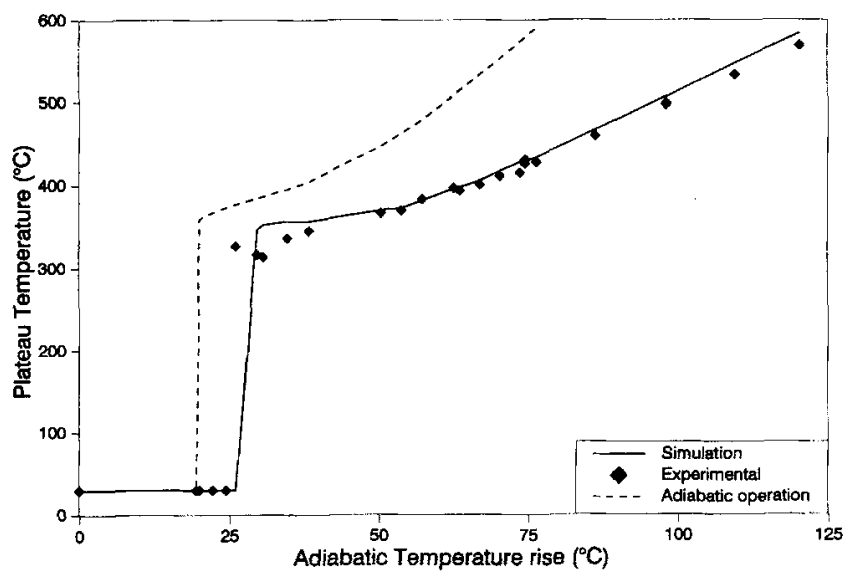

Figure 12. Plateau temperature as a function of the adiabatic temperature rise: comparison to adiabatic operation.

$u_{g}=0.40 \mathrm{~m} / \mathrm{s} ; t_{c}=400 \mathrm{~s} ; P=1.45 \mathrm{bar} ; T_{0}=30^{\circ} \mathrm{C}$.

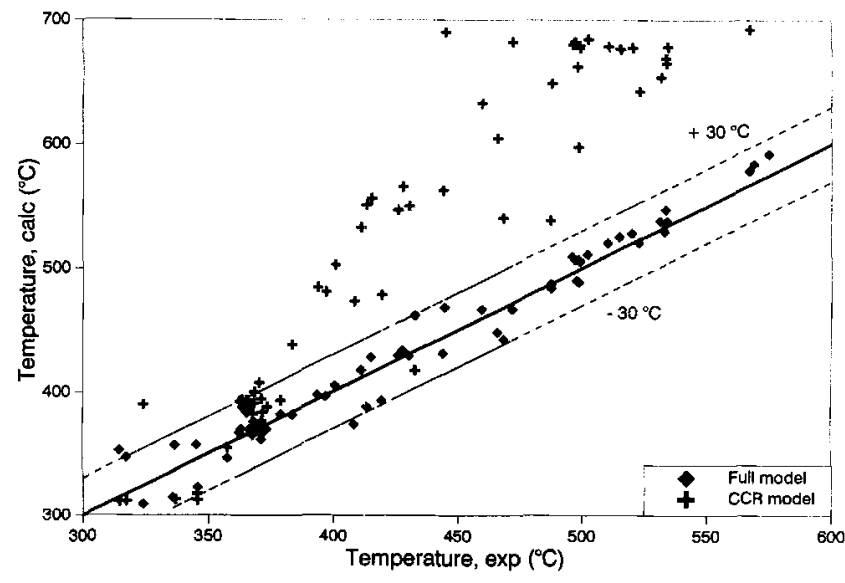

Figure 13. Comparison of experimentally measured plateau temperature to the plateau temperature calculated with the complete model.

\section{Conclusions}

Experimental results of the purification of polluted air by catalytic oxidation in a reverse-flow reactor have been compared to model simulations. A one-dimensional heterogeneous model has been applied to describe the reactor behavior. A heat-transport term is included to account for heat losses in the radial direction. Additionally a heat balance for the reactor wall has been introduced, since the heat capacity of the wall is significant. This may influence the behavior of the reactor, but it turned out to be significant only for large cycle periods. Kinetic parameters have been determined independently (see van de Beld et al., 1994b). Mass- and heattransport relations have been taken from the literature.

Generally, the experimental results are predicted accurately by the model. The deviations are mainly caused by inaccurate kinetic data and experimental errors. For low gas velocities the model is incapable of describing the experiments properly. Probably under these conditions an ODM is no longer sufficient in view of the severe radial temperature gradients. The ODM predicts the mean radial temperature well, but the difference between the mean and maximum temperatures over the radius can become quite large. However, as in practice flow reversal reactors will be run at high gas velocities, the ODM as developed will give more than satisfactory results in industrial applications.

\section{Acknowledgment}

These investigations were supported by the Netherlands' Foundation for Chemical Research (SON) with financial aid from the Netherlands' Technology Foundation and DSM.

\section{Notation}

$a_{p}=$ particle external surface area per unit particle volume, $\mathrm{m}^{2} / \mathrm{m}^{3}$

$a_{w}=$ specific internal wall area per unit reactor volume, $\mathrm{m}^{2} / \mathrm{m}^{3}$

$C_{p}=$ heat capacity, $\mathrm{kJ} / \mathrm{kg} \cdot \mathrm{K}$

$\mathcal{C}=$ concentration, $\mathrm{mol} / \mathrm{m}^{3}$

$D=$ diffusion coefficient, $\mathrm{m}^{2} / \mathrm{s}$

$D_{\text {eff }}=$ axial dispersion coefficient per unit gas volume, $\mathrm{m}^{2} / \mathrm{s}$

$D_{t}=$ reactor inner diameter, $\mathrm{m}$

$d_{c}=$ diameter of sphere with the equivalent external surface, see Table 2, $\mathrm{m}$

$d_{h}=$ hydraulic diameter, see Table 2 


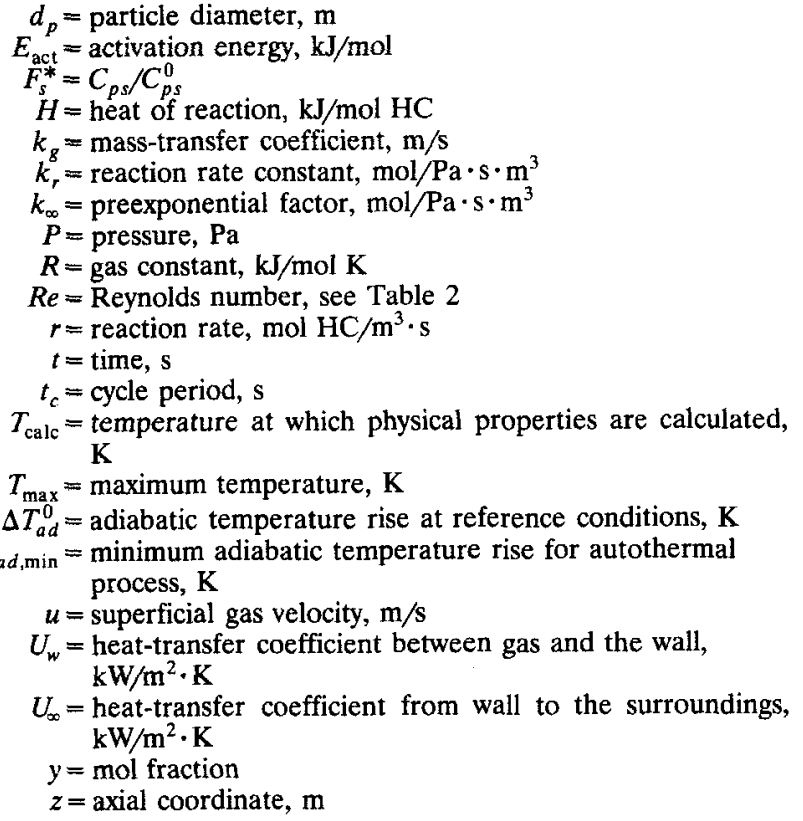

\section{Greek letters}

$\alpha_{p}=$ heat-transfer coefficient for the particle, $\mathrm{kW} / \mathrm{m}^{3} \cdot \mathrm{K}$

$\alpha_{w}=$ heat-transfer coefficient at the wall, $\mathrm{kW} / \mathrm{m}^{3} \cdot \mathrm{K}$

$\delta_{w}=$ reactor wall thickness, $\mathrm{m}$

$\epsilon=$ bed porosity

$\rho=$ density, $\mathrm{kg} / \mathrm{m}^{3}$

$\lambda_{\text {eff }}=$ effective axial thermal conductivity per unit gas volume, $\mathrm{kW} / \mathrm{m} \cdot \mathrm{K}$

$\lambda_{\text {eff, } r}=$ effective radial thermal conductivity, $\mathrm{kW} / \mathrm{m} \cdot \mathrm{K}$

$\theta=T / T_{0}$, dimensionless temperature

$\omega=z / L$, dimensionless axial position

$\lambda_{w}=$ thermal conductivity of the reactor wall, $\mathrm{kW} / \mathrm{m} \cdot \mathrm{K}$

\section{Subscripts and superscripts}

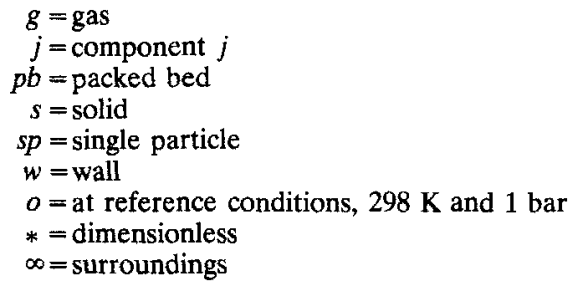

\section{Dimensionless groups}

$A^{*}=\left[4 \delta_{w}\left(D_{t}+\delta_{w}\right] / D_{t}^{2}\right.$, ratio of the cross-sectional surfaces of the wall and the reactor

$B o_{h}=\left[\left(\rho C_{p}\right)_{g 0} u_{g 0} d_{h}\right] / \epsilon \lambda_{\text {eff }}$, Bodenstein number for heat, Table 2

$B o_{m}=\left(u_{g 0} d_{h}\right) / \epsilon D_{\text {eff }}$, Bodenstein number for mass, Table 2

$D a=\left(r_{1}^{0} L\right) \wedge\left(u_{g 0} C_{1}^{0}\right)$, Damköhler number

$F=\left[(1-\epsilon)\left(\rho C_{p}\right)_{s 0} \backslash \boldsymbol{M}\left(\rho C_{p}\right)_{g 0}\right]$, extraction factor for heat

$\left.F_{w}^{*}=\left(\rho C_{p}\right)_{w} \lambda(1-\epsilon)\left(\rho C_{p}\right)_{s 0}\right]$, ratio of the heat capacity of the wall and the packed bed

$\mathrm{NTU}_{h}=\left[\alpha a_{p}(1-\epsilon) L \backslash \backslash\left(\rho_{0} C_{p}\right)_{g} u_{g 0}\right]$, number of heat-transfer units

$\mathrm{NTU}_{m j}=\left[k_{g j} a_{p}(1-\epsilon) L\right] / u_{g 0}$, number of mass-transfer units for transfer of component $j$

$\mathrm{NTU}_{w}=\left[U_{w} a_{w} L \backslash\left(\rho C_{p}\right)_{g 0} u_{g 0}\right]$, number of heat-transfer units at the reactor wall

$\left.\mathrm{NTU}_{\infty}=\left[U_{\infty} a_{w} L\right] \backslash\left(\rho C_{p}\right)_{g 0} u_{g 0}\right]$, number of heat-transfer units in the evaculated jacket

$N u=\left[\alpha_{p} d_{c} \vee \lambda_{g}\right.$, Nusselt number for interparticle heat transport, Table 2

$N u_{w}=\left[U_{w} d_{h}\right] / \lambda_{g}$, Nusselt number for overall heat transfer from the packed bed to the wall, Table 2
$P e_{h}=\left[u_{g 0}\left(\rho C_{p}\right) / g 0 L\right] / \epsilon \lambda_{\text {eff }}$, Peclet number for heat

$P e_{m}=\left[u_{g 0} L \backslash / \epsilon D_{\text {eff }}\right.$, Peclet number axial mass diffusion

$P e_{w}=\left[\left(\rho C_{p}\right)_{g 0} u_{g 0} L \bigvee \lambda_{w}\right.$, Peclet number for the reactor wall

$P r=\eta C_{p} / \lambda_{g}$, Prandtl number

$S c=\eta \rho D$, Schmidt number

$S h=\left(k_{g} d_{c}\right) / D_{j}$, Sherwood number, Table 2

$\left.\Delta \theta_{a d}=\left(H_{1} C_{1}^{0}\right) \bigwedge\left(\rho C_{p}\right)_{g 0} T_{0}\right]$, dimensionless adiabatic temperature rise

$\left.\left.\tau=\left[\left(u_{g 0} t\right) / \epsilon L\right)\right] \Lambda(1 / F)\right]$, dimensionless time: time divided by the residence time of the heat front

$\left.\tau_{c}=\left[\left(u_{g 0} t_{c}\right) / \epsilon L\right) \backslash(1 / F)\right]$, dimensionless cycle period: cycle period divided by the residence time of the heat front

\section{Literature Cited}

Bauer, R., "Effektive radiale Wärmeleitfähigkeit gasdurchstrssömter Schüttungen mit Partikeln unterschiedlicher Form and Grö $\beta$ enverteilung," VDI-Forschungsheft, 582 (1977).

Blanks, R. F., T. S. Wittrig, and D. A. Peterson, "Bidirectional Adiabatic Synthesis Gas Generator," Chem. Eng. Sci., 45, 2407 (1990)

de Wasch, A. P. de, and G. F. Froment, "Heat Transfer in Packed Beds," Chem. Eng. Sci., 27, 567 (1972).

Dixon, A. G., and D. L. Cresswell, "Theoretical Prediction of Effective Heat Transfer Parameters in Packed Beds," AIChE J., 25, 663 (1979).

Edwards, M. F., and J. F. Richardson, "Gas Dispersion in Packed Beds," Chem. Eng. Sci., 23, 109 (1968).

Eigenberger, G., and U. Nieken, "Catalytic Combustion with Periodic Flow Reversal," Chem. Eng. Sci., 43, 2109 (1988).

Gnielinski, V., "Berechnung des Wärme- and Stofaustauschs in Durchströmten Ruhenden Schüttungen," Verfahrenstechnik, 16, 36 (1978).

Gosiewski, K., "Dynamic Modelling of Industrial $\mathrm{SO}_{2}$ Oxidation Reactors: II. Model of a Reverse-Flow Reactor," Chem. Eng. Proc., 32, 233 (1993)

L'Air Liquide, Division Scientifique, Encyclopedia dez Gaz, Elsevier, Amsterdam, The Netherlands (1976).

Martin, H., "Low Peclet Number Particle to Fluid Heat and Mass Transfer in Packed Beds," Chem. Eng. Sci., 33, 913 (1978).

Matros, Yu. Sh., Catalytic Processes under Unsteady-State Conditions, Studies in Surface Science and Catalysis, Vol. 43, Elsevier, Amsterdam, The Netherlands (1989).

Matros, Yu. Sh., A. S. Noskov, V. A. Chumachenko, and O. V. Goldman, "Theory and Application of Unsteady Catalytic Detoxication of Effluent Gases from Sulfur Dioxide, Nitrogen Oxides and Organic Compounds," Chem. Eng. Sci., 43, 2061 (1988).

Matros, Yu. Sh., A. S. Noskov, and V. A. Chumachenko, "Progress in Reverse-Process Application to Catalytic Incineration Problems," Chem. Eng. Proc., 32, 89 (1993).

Sapundzhiev, Kh., G. A. Bunimovich, V. I. Drobyshevich, G. Grozev, L. V. Yausheva, and Yu. Sh. Matros, D. Elenkov, "Effect of Heat Loss on Operation of Reactors with Periodic Reverse Gas Feed," Theor. Found. Chem. Eng., 22, 258 (1989).

Schoubye, P., and P. E. Nielsen, "Topsoe Process Combines Catalytic Combustion with Regenerative Heat Transfer," AIChE Meeting, Princeton Univ., Princeton, NJ (June, 1993).

van de Beld, L., and K. R. Westerterp, "Air Purification by Catalytic Oxidation in a Reactor with Periodic Flow Reversal," Chem. Eng. Technol, 17, 217 (1994).

van de Beld, L., R. A. Borman, O. R. Derkx, B. A. A. van Woezik, and K. R. Westerterp, "Removal of Volatile Organic Compounds from Polluted Air in a Reverse Flow Reactor: An Experimental Study," Ind. Eng. Chem. Res., 33, 2946 (1994a).

van de Beld, L., M. P. G. Bijl, A. Reinders, B. van der Werf, and K. R. Westerterp, "The Catalytic Oxidation of Organic Contaminants in a Packed Bed Reactor," Chem. Eng. Sci., 49, 4361 (1994b).

Vortmeyer, D., "Radiation in Packed Solids," Ger. Chem. Eng., 3 124 (1980).

Wakao, N., and S. Kaguei, Heat and Mass Transfer in Packed Beds, Gordon \& Breach, New York (1982).

Westerink, E. J., N. Koster, and K. R. Westerterp, "The Choice Between Cooled Tubular Reactor Models: Analysis of the Hot Spot," Chem. Eng. Sci., 45, 3443 (1990).

Manuscript received Jan. 17, 1995, and revision received July 17, 1995 